\title{
İkili Karşılaştırmalar Yargılarına ve Sıralama Yargılarına Dayalı Ölçekleme Yaklaşımlarının Karşılaştırılması*
}

\author{
A Comparison of Scaling Procedures Based on Pair-Wise \\ Comparison and Rank-Order Judgments Scaling
}

\author{
Aylin ALBAYRAK SARI** $\quad$ Selahattin GELBAL***
}

$\ddot{O} z$

Bu çalışmanın amacı, yargıcı kararlarına dayalı iki ölçekleme yöntemi ile elde edilen sonuçları karşılaştırarak alana katkı sağlamak olarak belirlenmiştir. Çalışma, Hacettepe Üniversitesi Fen Bilgisi Öğretmenliğinde okuyan 194 öğretmen adayı ile yürütülmüş ve öğretmen adaylarının interneti kullanma nedenlerine ilişkin görüşleri alınmıştır. İki farklı form ile öğretmen adaylarından belirtilen internet kullanım amaçlarını ikili olarak karşılaştırmaları ve sıralamaları istenmiş, toplanan bu veriler üzerinde ikili karşılaştırma ve sıralama yargılarına dayalı ölçekleme işlemleri uygulanmıştır. Farklı iki yöntemle elde edilen ölçekleme işlemleri sonucunda elde edilen ölçek değerleri arasındaki tutarlılık Spearman-Brown sıra farkları korelâsyon katsayısı $\left(r_{s}\right)$ ile hesaplanmıştır $(r=0.09, p>0.05)$. Bu bulguya dayanarak bu iki ölçekleme yaklaşımının benzer sonuçlar üretmediği, bu nedenle ölçekleme çalışmalarında seçilecek olan ölçekleme yöntemine karar verilirken kullanılacak yöntemin sayıltılarına dikkat edilmesi gerektiği ifade edilmiştir.

Anahtar Kelimeler: Ölçekleme, İkili Karşılaştırma Yargılarına Dayalı Ölçekleme, Sıralama Yargılarına Dayalı Ölçekleme.

\begin{abstract}
This study aims to provide an insight into the scaling model used in social sciences and to determine whether the two scaling method produces similar results based on the judgements decision. The study conducted 194 preservice teachers in the department of Science Teacher Education at Hacettepe University. The scaling procedure was conducted to get scaling values for pair-wise comparison and ranking judgment on the collected data. The Spearmen-rho correlation coefficient which was calculated to examine the consistency between the scale values was found 0,09 at a 0,05 significance level and this value was not significant $(r=0.09, p>0.05)$. Based on these findings, these two scaling approaches didn't produce similar conclusions so it can be said that attention should be paid to the selected scaling methods and assumptions in study of scaling.
\end{abstract}

Key Words: Scaling, Pair-Wise Comparision Judgments Scaling, Rank-Order Judgments Scaling.

\section{GIRIŞ}

İnternet ağını kullanarak milyonlarca insan fiziksel olarak birbirinden uzakta olsa da birbiri ile iletişim kurmakta ve bilgi alışverişinde bulunmaktadır. Günümüz bilgi çağında, bireylerden beklenen bilgiye ulaşabilen, bilgiyi kullanabilen ve bu bilgileri kullanarak yeni bilgiler üretebilen bireyler olmalarıdır. Bu değişim, eğitim sisteminin de bu değişimle paralel olarak yeniden gözden geçirilmesini gerektirmektedir.

İnterneti kullanan öğrencilerin iletişim kurma, araştırma yapma, bilgiye ulaşma ve paylaşma becerileri daha çok gelişmekte ve bu öğrencilerin mezuniyet sonrasında bilgi okuryazarı bireyler olarak bilgi-merkezli teknolojik bir ortamda daha avantajlı konuma

\footnotetext{
* Bu çalışmanın bir bölümü 21. Ulusal Eğitim Bilimleri Kongresi’nde sözlü bildiri olarak sunulmuştur.

** Dr., Hacettepe Üniversitesi, Eğitim Fakültesi, Ankara-Türkiye, e-posta: aylinalb@ hacettepe.edu.tr

*** Prof. Dr., Hacettepe Üniversitesi, Eğitim Fakültesi, Ankara-Türkiye, e-posta: gelbal@ hacettepe.edu.tr
} 
gelmelerini sağlamaktadır (Altun Akbaba ve Altun, 2000). Diğer yandan internet, öğrencilerin problem çözme, iletişim, eleştirel düşünme becerilerini artırırken yaş, sınıf, cinsiyet, milliyet, din ve özel ihtiyaçlar gibi bireysel farklılıklarını da önemli ölçüde ortadan kaldırılabilmekte, günümüz üniversite öğrencilerinin sosyal yaşamlarının nitelik ve nicelik olarak gelişmesinde önemli bir araç rolü oynamaktadır (Ergün, 1998; Douglas ve ark., 2008). Dolayısıyla gelecek nesilleri yetiştirecek öğretmen adaylarının interneti kullanım amaçlarının belirlenmesinin önemli olduğu düşünülmektedir. Bu problemi araştırabilmek için iki farklı ölçekleme yöntemi kullanılarak ve bu ölçekleme yöntemlerinin sonuçları karşılaştırılmıştır.

Ölçekleme işlemleri psikofizik adı verilen, fiziksel büyüklüklerin bireyler tarafından nasıl algılandığını ortaya çıkarmak ile ilgilenen bilim dalında karşımıza çıkmıştır. Psikofizik bilimi uyarıcıların fiziksel değerleri ile algılanan psikolojik boyut arasındaki bağıntıyı belirleyen kanunları bulmak ile ilgilenir (Turgut ve Baykul, 1992). Şekil 1'de uyarıcıların ölçülen özellikleri ile algılanan özellikleri arasındaki ilişki şematize edilmiştir.

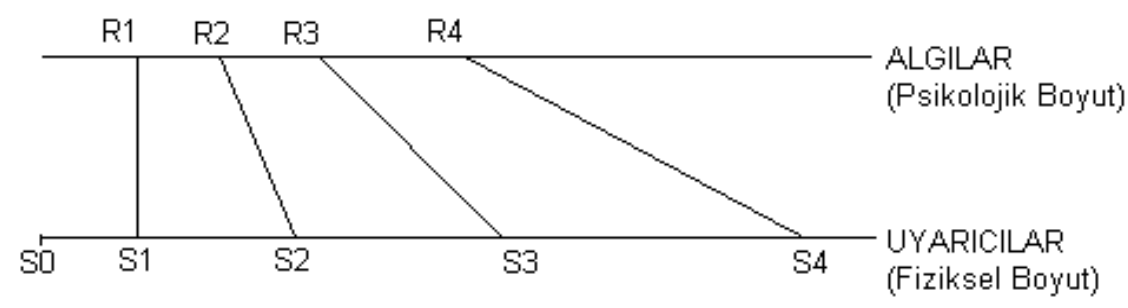

Şekil 1. Uyarıcıların Ölçülen Özellikleri İle Algılanan Özellikleri Arasındaki İlişki

(Kaynak: Turgut ve Baykul, 1992)

Ölçekleme yöntemleri, temelde yargıcı kararları veya denek tepkileri olmak üzere iki kaynağa dayalıdır. Denek tepkilerine dayalı yaklaşımlara tepki yaklaşımı, gözlemci yargılarına dayalı yaklaşımlara ise yargı yaklaşımı adı verilmektedir. Ölçeklemenin amacı, gözlemci yargılarından veya denek tepkilerinden elde edilen verilere istatistiksel işlemler uygulayarak, daha iyi niteliklerde bir ölçek elde edebilmektir (Turgut ve Baykul, 1992).

Yargı yaklaşımına dayalı ölçekleme yöntemlerinde gözlemcilerden tarafsız olarak her bir uyarıcının diğer uyarıcılara göre bağıl durumunu belirlemeleri istenir. Yargıcı kararlarına dayalı ölçekleme yaklaşımı, uyarıcıları uzman ya da bilirkişi yargılarına dayalı olarak belirli bir boyutta ölçeklemeyi içerir. Denek tepkilerine dayalı yaklaşımlar madde ya da uyarıcının değil cevapların ölçeklenmesi amacını güder (Torgerson, 1958; Tezbaşaran, 2004).

Bu çalışmada yargıcı kararlarına dayalı farklı ölçekleme yöntemler sonucunda elde edilen ölçek değerlerinin psikofiziksel boyuttaki yerlerinin yani ölçek değerlerinin karşılaştırılması amaçlanmıştır. Gözlemci yargılarına dayalı ölçekleme yaklaşımlarından ikili karşılaştırmalarla ölçekleme ve sıralama yargılarıyla ölçekleme yöntemleri ve bu ölçekleme yöntemlerinden elde edilen sonuçların tutarlılığı üzerinde durulmuştur.

İkili karşılaştırma yargılarına dayalı ölçekleme yöntemi basit bir ikili karşılaştırmadır. Bu ölçekleme yöntemi başlangıçta tutum cümlelerinin ölçeklemesinde kullanılsa da cevaplayıcıların uyarıcıları ikişerli olarak değerlendirebileceği her durumda kullanılabilir. Bu nedenle yöntemin oldukça geniş bir uygulama alanı vardır (Anıl ve Güler, 2006). Bu yöntem basit olmasının yanı sıra, karşılaştırmalı yargıların tümünü kapsamaktadır (Brown ve Peterson, 2009). İkili karşılaştırmalar yönteminde $\mathrm{N}$ tane gözlemciye $U_{\mathrm{j}}$ ve $U_{k}$ uyarıcılarından hangisinin uyarıcılık değerinin daha büyük olduğu sorulur. Örneğin gözlemciler belirtilen iki uyarıcıdan hangisinin "daha büyük", "daha iyi”, "daha verimli" 
olduğuna karar verirler. İkili karşılaştırmalar için ölçek değerleri Thurstone'un karşılaştırmalı yargı kanunu (Thurstone, 1958) kullanılarak hesaplanır. İkili karşılaştırma yönteminin uygulanmasında beş hal belirtilmiştir. $\mathrm{Bu}$ çalışmada ikili karşılaştırmalar ölçeklemesinde III. Hal ve V. Hal denklemi ile ölçekleme yapılmaktadır (Guilford, 1954; Torgerson, 1958; Turgut ve Baykul, 1992).

Turgut ve Baykul (1992) sıralamayı, "uyarıcıları belirli bir nitelikte büyükten küçüğe ya da küçükten büyüğe doğru sıralayarak her birine sıradaki yerine göre bir sıra sayıs1 verme işlemi” olarak tanımlamaktadır. Sıralama, sıralanan uyarıcılar arasındaki büyüklük küçüklük ilişkilerini de belirlediğinden ikili karşılaştırmalar yöntemine benzemektedir. Sıralama verileriyle yapılan ölçekleme işlemlerinde, ikili karşılaştırmalar yönteminde sıkça karşılaşılan çelişkili üçlülerin olmamasından dolayı daha tutarlı sonuçlar elde edilebilmektedir (Turgut ve Baykul, 1992). Sıralama yöntemi gözlemciyi uyarıcılar arasında mümkün olan en büyük ayrımı yapmaya zorladığı için gözlemcinin bu ayrımı yapabildiği hallerde geçerliği çok yüksek bir ölçek vermekte, bu nedenle iç tutarlılık yüksek olmakta ve sıralama yargılarıyla ölçekleme, bir sıra numarası verilebilecek tüm uyarıcılara uygulanabilmektedir (Guilford, 1954; Turgut ve Baykul, 1992). Siralama yargilarına dayalı ölçekleme yapılabilmesi için öncelikle gözlemcilere uyarıcıların tamamı verilir. Gözlemcilerin her bir uyarıcıyı diğer tüm uyarıcılarla karşılaştırarak bir sıra numarası verdiği temel sayıltısı ile gözlemciden uyarıcıları sıralaması istenir. Yapılan bir dizi istatistiksel işlem sonucunda ölçek değerleri elde edilir (Turgut ve Baykul, 1992).

Tezbaşaran (2004) alanyazın taraması yaptığı çalışmasının bulgularında ölçekleme konusunda yapılan çalışmaların çok sınırlı olduğunu rapor etmiştir. Alanyazın incelendiğinde ölçekleme yöntemleri konusunda sınırlı sayıda çalışma olduğu fark edilmiştir. Özellikle farklı ölçekleme sonuçlarının karşılaştırıldığı çalışmaların sayısının çok daha az olduğu görülmektedir.

Anıl ve Güler (2006) yaptıkları çalışmada, ikili karşılaştırma yöntemi ile ölçekleme çalışması yapmışlar, nitelikli bir öğretmenin sekiz özelliğin ikişerli gruplar hâlinde öğretmen adaylarına vererek, bir öğretmende bulunması istenen öğretmen özelliklerini belirlemeye çalışmışlardır. Bulgular, nitelikli bir öğretmende bulunması istenilen birinci özelliğin meslek sevgisi olduğunu ortaya çıkarmıştır.

Öğretmen (2008) çalışmasında, araştırmacı tarafından geliştirilen Alan Tercih Envanterinin geçerlik ve güvenirlik analizlerini, ikili karşılaştırmalara dayalı yarg1 kanununun V. Hal denklemi ile yapmıştır. Uygulama yapılan gruplara ait ölçek değerlerinin iç tutarlılık sonuçlarının ki-kare analizi ile elde edildiği ifade edilmiştir.

Kan (2008a) çalışmasını, yargıcı kararlarına dayalı farklı iki ölçekleme yöntemi ile elde edilen sonuçları karşılaştırmak amacıyla, 84 akademisyen ve psikolog ile Bağımlılık Yapıcı Maddelere yönelik denemelik tutum ölçeği kullanarak yürütmüştür. Toplanan veriler ile sınıflama ve sıralama kararlarına dayalı ölçekleme işlemleri uygulamış ve elde edilen ölçek değerleri arasındaki tutarlılık, hesaplanan Spearman rho (rs) korelasyon katsayısı ile incelenmiştir. Elde edilen korelasyon katsayısı göre, bu iki ölçekleme yaklaşımının benzer sonuçlar üretmediği belirtilmiştir $\left(r_{s}=0.20\right)$.

Kan (2008b) sosyal bilimlerde ve özellikle eğitim ve psikolojide kullanılan ölçekleme modellerine genel bir bakış açısı oluşturmak ve bu ölçekleme modelleri aracılığıyla elde edilen ölçek değerleri ve psikometrik özellikleri arasındaki tutarlığı belirlemeyi amacıyla bir çalışma yapmıştır. Bağımlılık Yapıcı Maddelere yönelik denemelik tutum ölçeği kullanarak denek tepkilerine ve yargıcı kararlarına dayalı ölçekleme işlemleri uygulamıştır. Elde edilen ölçek değerleri arasındaki tutarlılığı incelemek için ise Spearman rho $\left(r_{s}\right)$ korelasyon katsayısı hesaplanmış ve ölçek değerleri arasında orta derecede anlamlı bir ilişki olduğunu belirtilmiştir. 
Brown ve Peterson (2009) çalışmalarında, ikili karşılaştırma yöntemi hakkında bilgi vererek, geçerlik ve güvenirlik uygulamalarını örneklerle destekleyerek açıklamışlardır.

Güler ve Anıl (2009) ikili karşılaştırma yöntemini kullanarak lisansüstü öğrencilerinde bulunması istenen özellikleri araştırmışlardır. Araştırma bulgularında, öğrencilerde bulunması istenen birinci özelliğin akademik başarı puanı olduğu belirtilmiştir. $\mathrm{Bu}$ özelliği sırasıyla, öğrencinin mülakat puanı, programa girme amacı, İngilizce yeterlik puanı, ALES puanı, bölüm öğrencisi olup olmaması ve referansının olup olmaması özelliklerinin izlediği ifade edilmiştir.

Özer ve Acar (2011), ikili karşılaştırma yönteminin V. Hal denklemini kullanarak öğretmen yeterliklerini araştırmışlar ve çalışmaya katılan öğrencilere göre, bir öğretmende bulunması gereken özelliklerden birinci özelliğin öğrenciyi tanıma özelliği olduğunu belirtilmişlerdir.

Öztürk, Özdemir ve Gelbal (2011) tarafından yapılan araştırmada sınıflama yargılarına dayalı ölçekleme ve denek tepkilerine dayalı ölçekleme işlemi ile elde edilen ölçek değerleri arasındaki tutarlılığın belirlenmesi amaçlanmıştır. Araştırma sonucunda, iki farklı ölçekleme yaklaşımına göre elde edilen ölçek değerleri Wilcoxon İşaretli Sıralar testi ile karşılaştırılmış ve aralarında pozitif ve orta düzeyde $(\mathrm{r}=0.45)$ bir ilişki olduğu ifade edilmiştir.

Bal (2011) çalışmasında, sıralama yargıları kanunuyla ölçekleme yaparak, öğrencilerin seviye belirleme sınavı (SBS) başarılarında etkili olan faktörleri belirlemeye çalışmıştır. Çalışma sonucunda elde edilen bulgulara göre, bireysel özellikler (başarma isteği, kendine güven, dikkat, güdü gibi) öğrencilerin SBS başarılarını etkileyen faktörlerin başında gelmektedir. Bireysel özellikleri sırasıyla, öğrencinin çalışma yöntemi ile sınava hazırlanırken yakın cevreden aldığı destek faktörleri izlemektedir. Dershaneye gitme, özel ders alma, soru çözme ve öğretmen desteği faktörleri ise, daha alt sıralarda yer almıştır. Ayrıca öğrenciler, sosyal etkinlikler faktörüne en son sırada yer vermişlerdir.

Ekinci, Bindak ve Yıldırım (2012) çalışmasında ikili karşılaştırmalar yöntemi ile ölçekleme yaparak, öğretmenlerin ve okul yöneticilerinin görüşlerini almıştır. Öğretmenlerin mesleki sorunlarının araştırıldığı bu çalışma, sonucunda okul yöneticilerinin ve öğretmenlerin sorunları farklı sıralara yerleştirdikleri gözlenmiştir.

Acar Güvendir ve Özer Özkan (2013) tarafindan gerçekleştirilen çalışmada yargıcı kararlarına dayalı ölçekleme yöntemlerinden ikili karşılaştırma ve sıralama yargılarına dayalı ölçekleme yöntemlerinden elde edilen ölçek değerleri arasındaki tutarlılık araştırılmıştır. Her iki yöntemle elde edilen ölçek değerleri arasındaki tutarlılığı belirlemek amacıyla Spearman-Brown sıra farkları korelasyon katsayısı hesaplanmıştır. Elde edilen sonuca göre iki ölçekleme yöntemi benzer sonuçlar üretmektedir.

Altun ve Gelbal (2014) çalışmasında ölçme değerlendirme yöntem ve araçlarının öğretmen yargılarına dayalı olarak ikili karşılaştırma yöntemiyle ölçeklenmesini amaçlamışlardır. Çalışma sonucunda, öğretmenlerin birinci sırada performans değerlendirme yöntemini kullandıkları bulgusuna ulaşılmıştır.

Polat ve Göksel (2014) ikili karşılaştırma yöntemini kullanarak öğretmen adaylarının sosyal aktivite tercihlerinin bulundukları üniversitelere göre değişip değişmediğini karşılaştırmışlardır. Araştırmanın sonucunda, iki farklı üniversitede öğrenim gören öğretmen adaylarının sosyal aktivite tercihlerinin birbiriyle uyumlu olduğu sonucuna ulaşılmıştır.

Yapılan çalışmalar incelendiğinde, yapılan çalışmaların genel olarak tek bir ölçekleme yöntemi kullanılarak yapıldığı, iki farklı ölçekleme yöntemi sonuçlarının karşılaştırıldığı çalışmaların ise çok sınırlı olduğu görülmüştür. Farklı iki ölçekleme yöntemi sonuçlarının karşılaştırılmasının alana katkı sağlayacağı düşünülmektedir. Bu çalışmada ikili 
karşılaştırma ve sıralama yargılarına dayalı ölçekleme ile elde edilen sonuçlar arasındaki tutarlılığının incelenmesi amaçlanmıştır. Bu doğrultu da aşağıdaki sorulara yanıt aranmıştır.

1. İkili karşılaştırma yargılarına dayalı ölçekleme yönteminden elde edilen madde ölçek değerleri nasıldır?

2. Sıralama yargılarına dayalı ölçekleme yönteminden elde edilen madde ölçek değerleri nasildir?

3. İkili karşılaştırma yargılarına dayalı olarak elde edilen ölçek değerleri ile sıralama yargılarına dayalı olarak elde edilen ölçek değerleri arasında nasıl bir ilişki vardır?

\section{Araştırmanın Amacı}

$\mathrm{Bu}$ çalışmanın amacı, yargıcı kararlarına dayalı ölçekleme yöntemlerinden ikili karşılaştırma ve sıralama yargılarına dayalı ölçekleme yöntemi ile ölçekleme yaparak elde edilen ölçek değerlerinin tutarlılığını karşılaştırmaktır. Bu iki farklı yöntem sonucu elde edilen ölçek değerlerinin kullanılan yönteme göre nasıl değerler alacağ incelenmiştir.

Davranış bilimleri alanına giren herhangi değişkenin ölçümünde en iyi yolun araştırılması gerekli ve önemli bir unsurdur (Tezbaşaran, 1996; Crocker \& Algina 1986). Bu açıdan ele alındığında çalışmanın davranış bilimlerine ait bir değişkeni ölçmek için kullanılabilecek iki yaklaşımda nasıl sonuçlar elde edildiğinin ve bu sonuçların tutarlılı̆̆ının belirlenmesinin alana katkı getirebileceği söylenebilir. Araştırmanın bu alanda sınırlı olan çalışmalara katkı sağlayacağı düşünülmektedir.

\section{YÖNTEM}

\section{Araştırma Deseni}

Araştırmada ikili karşılaştırma ve sıralama yargılarına dayalı ölçekleme yöntemleri ile ölçekleme yapılmış ve iki farklı yöntem ile elde edilen ölçek değerlerinin tutarlılığı araştırılmıştır. Araştırmada evrene genelleme amacı bulunmamaktadır. $\mathrm{Bu}$ nedenle araştırma, temel araştırma niteliğindedir.

\section{Çalışma Grubu}

Araştırmanın örneklemini, Hacettepe Üniversitesi Eğitim Fakültesi Fen Bilgisi Öğretmenliğinde okuyan 194 öğretmen adayı oluşturmaktadır. Örneklemde yer alan öğretmen adaylarının tamamı zorunlu bilgisayar dersini almış üçüncü ve dördüncü sınıfta öğrenimine devam eden öğretmen adaylarıdır. Araştırmada amaçlı örneklem yöntemlerinden uygun örnekleme yolu ile örneklem seçilmiştir. Uygun örnekleme yöntemi, zaman, para ve işgücü açısından örneklemin kolay ulaşılabilir ve uygulama yapılabilir birimlerden seçilmesi ile yapılır (Büyüköztürk, 2012).

\section{Veri Toplama Aracı}

Çalışmada kullanılacak ölçme aracındaki uyarıcıların belirlenebilmesi için, öncelikle eğitim fakültesi ilköğretim bölümünde öğrenimine devam eden ve interneti aktif kullandığını ifade eden 15 son sınıf öğretmen adayı ile görüşme yapılarak interneti en çok hangi amaçlarla kullandıklarını belirtmeleri istenmiştir. Bu listedeki interneti kullanım amaçları ve yapılan alanyazın taramaları dikkate alınarak, öğretmen adaylarının interneti kullanım amaçlarının neler olduğu belirlenmiştir. Belirlenen bu amaçlar bilgisayar ve öğrenim teknolojileri bölümünde görev yapan ve öğretmen adaylarına bilgisayar dersi veren iki uzmandan uzman görüşü alınmış ve internet kullanımına dair sekiz farklı amaç belirlenerek iki ölçme aracı hazırlanmıştır. 


\section{Verilerin Analizi}

İkili karşılaştırmalar yargıları ile ölçekleme ve sıralama yargıları ile ölçekleme işlemleri için farklı yönergelere sahip, iki farklı form düzenlenmiştir.

İkili karşılaştırmalar ile ölçekleme yönteminde veriler öncelikle V. Hal denklemi ile ölçeklenmiş ve uyum ölçüsü kontrol edilmiş, daha sonra ise III. Hal denklemi ile ölçeklenmiştir. Her bir öğretmen adayından belirlenen sekiz amacı ikili olarak karşılaştırmaları ve interneti verilen ikili durumlardan hangisi için daha sık kullandıklarını belirtmeleri istenmiştir. Her bir öğretmen adayının yaptığ olarak girilmiş ve o öğretmen adayının cevaplarında çelişkili üçlüler olup olmadığı ki kare değerleri ile kontrol edilmiştir. Yanıtlarında çelişkili üçlü olan öğretmen adaylarının yanıtları çalışmadan çıkarılmış ve 194 öğretmen adayı ile ölçekleme çalışmasına devam edilmiştir. Her bir duruma ait frekans değerleri belirlenmiş ve frekans matrisi (F), F matrisinin her bir hücresindeki değer toplam kişi sayısına $(\mathrm{N}=194)$ bölünerek oranlar matrisi ve oranlar matrisindeki hücre değerlerine (P) karşılık gelen (Z) standart değerleri belirlenerek birim normal sapmalar matrisi elde edilmiştir. Matrisin sonunda her bir sütuna ait değerlerin toplamı ve ortalaması hesaplanmıştır. Hesaplanan bu ortalama değerleri ölçek değerleri $\left(\mathrm{S}_{\mathrm{j}}\right)$ 'dir. Ölçek değerlerinin başlangıcı (0 noktası), bu satırdaki değerlerden en küçük olanına kaydırılarak ölçek değerleri $\left(\mathrm{S}_{\mathrm{c}}\right)$ sıralanmıştır. $\mathrm{Bu}$ işlemde; en küçük değer negatif ise tüm değerlere bu değerin mutlak değeri eklenerek değer 0'a çekilir, en küçük değer pozitif olduğunda ise tüm değerlerden bu değer çıkarılarak başlangıç noktası 0'a kaydırılmış olur. Bu işlem sonrasında her bir uyarıcının ölçek değeri sayı doğrusu üzerinde belirlenmiştir. Daha sonra elde edilen birim normal standart sapmalar (Z) matrisi kullanılarak uyum ölçüsü hesaplanmıştır.

Uyum ölçüsü olarak hesaplanan Ki-kare değeri (1178,77), 21 serbestlik derecesinde 0.05 anlamlılık düzeyinde manidar çıkmıştır. Ki-kare değerinin manidar olmasının nedeninin ölçeklenen değişkenin tek boyutlu olduğu düşünülmüş ve bu nedenle Guilford (1954)'un tavsiye ettiği III. Hal denklemiyle ölçekleme yapılmıştır.

V. Hal eşitliğgi ile yapılan ölçeklemede, ayırt etme yargıları dağılımlarının eşit ve bir ölçekleme denemesinde sabit olduğu varsayılmış; ayrıca $\sqrt{2 . \sigma}$ ölçeklemenin birimi olarak alınmıştır. Gözlemcilerin yargılarından elde edilen verilerin V. Hal'in şartlarını ve genelde konulan varsayımları sağlayıp sağlamadığını kontrol amacıyla yapılan Ki-kare testinin manidar çıkmasının V. Hal için kabul edilen varsayımların en az birini sağlamadığına veya gözlemci yargılarının tutarsızlığına işaret ettiği belirtilmiştir. Ki kare testinin manidar çıkmasına, V. Hal denkleminin çıkarılması sırasında konulan, ayırt etme varyanslarının tüm uyarıcılar için eşit olması varsayımı sebep olduysa bunun giderilmesi, V. Hal yerine III. Halin kullanılmasıyla mümkün olur.

III. Hal ile ölçekleme yapılırken standart sapmaların da bilinmesi gerekir. Ayırt etme yargılarının standart sapmaları Z matrisinden kestirilebilir. 194 öğretmen adayına internet kullanım amaçları ile ilgili yöneltilen soruya alınan yanıtlardan elde edilen bu frekansların $\mathrm{Z}$ birim matrisleri hesaplanmıştır. III. Hal denkleminde de bu Z birim normal sapmalar matrisi kullanılarak hesaplamalar yapılmıştır.

Öncelikle $\mathrm{Z}$ birim matrisinin sütun toplamları $\left(\Sigma Z_{j}\right)$ bulunarak, bu matrisin karesi hesaplanmıştır. $Z$ birim normal sapmalar karesi matrisinden sütun elemanlarının toplamı $\left(\Sigma\left(Z_{j}^{2}\right)\right)$ hesaplanarak, K ile yani uyarıcı sayısı ile çarpılmıştır $\left(K . \Sigma\left(Z_{j}^{2}\right)\right)$. Sütun toplamlarını elde ettiğimiz satırın karesi alınarak sütun toplamlarının karesi hesaplanmıştır $\left(\Sigma Z_{\mathrm{j}}\right)^{2}$. Daha sonra sütun elemanlarının standart kayması hesaplanarak $\left(\mathrm{V}_{\mathrm{i}}\right)$, sütun elemanlarının standart kayması $\mathrm{K}$ uyarıcı sayısı ile çarpılmıştır. $1 / \mathrm{K} . \mathrm{V}_{\mathrm{j}}$ hesaplanmış ve bu $1 / \mathrm{KV}_{\mathrm{j}}$ değerlerinin toplamı alınarak K.C sabiti hesaplanmıştır; 


$$
K . C=\frac{2 K}{\frac{1}{K V_{j}}}
$$

Ayırt etme yargılarının standart sapma değerinin hesaplanması için;

$$
\sigma_{j}=\frac{K . C}{K . V_{j}}-1
$$

formülünden faydalanılmıştır. $\mathrm{Bu}$ değerlerin karesi alınarak varyans değerleri bulunmuştur. Ayırt etme yargılarının varyansları kestirildikten sonra bu varyansların toplamı bulunmuştur. Bunun için varyanslar ikişer ikişer toplanarak esas köşegenin üstündeki hücreye yazılmış ve varyans toplamları matrisi elde edilmiştir. Bu matris elemanlarının karekökü alınarak varyans toplamlarının karekökü matrisinin esas elemanların her biri Z birim matrisinin elemanları ile çarpılarak $\mathrm{S}$ matrisi elde edilmiştir. $\mathrm{Bu}$ matrisin esas köşegenindeki elemanlar sıfırdır; esas köşegenin altında kalan elemanlar da esas köşegenin üstündeki elemanların işaretçe tersi, mutlak değerce eşitidir. Bu nedenle matrisin toplamı ve sütun ortalamaları toplamı sıfıra eşittir. $S$ matrisinin sütun elemanlarının toplanarak $\Sigma Z_{j}$ değerleri bulunmuştur. Daha sonra bu $\Sigma Z_{i}$ sütunundaki değerler, $K$ uyarıcı sayısına bölünerek sütun ortalamaları alınmış ve $S_{j}$ değerleri elde edilmiştir. En küçük ortalama sıfıra getirilerek, $S_{\mathrm{c}}$ ölçek değerleri bulunmuştur.

Sıralama yargıları ile ölçekleme yöntemi için aynı uyarıcılar (ölçek maddeleri) 194 öğretmen adayına verilmiş ve tüm uyarıcıları göz önünde tutarak, verilen uyarıcıları yani interneti kullanım amaçlarını, kullanım sıklıklarına göre sıralamaları istenmiştir. N gözlemcinin K uyarıcıyı belirli bir boyutta sıralamalarıyla elde edilen veriler, $\mathrm{N}$ satırlı ve $\mathrm{K}$ sütunlu, her satır bir gözlemcinin uyarıcılara verdiği sıra sayılarını gösteren, bir matriste toplanmıştır. $\mathrm{Bu}$ analizde, interneti kullanım amaçları olarak belirlenen 8 durum, 194 gözlemciden kullanılma sıklığına göre 1'den 8'e kadar sıraya koymaları istenmiştir. Sekiz durum için elde edilen veriler sıra farkları matrisinde toplanmış, 8 durum için elde edilen bu sira frekansları matrisinden;

$$
\begin{aligned}
& n\left(S_{A}>S_{B}\right)=f_{j i} \cdot\left(f_{k<i}+\frac{1}{2} \cdot f_{k i}\right) \\
& \text { eşitliği yardımıyla } n\left(S_{j i}>S_{k i}\right) \text { frekansları hesaplanarak } 7 \text { farklı matris }
\end{aligned}
$$

oluşturulmuştur. Her bir matrisin sütun elemanları toplamı bulunarak, frekans matrisinin (F) sütunları oluşturulmuştur. Frekans matrisinin elemanları $\mathrm{N}^{2}$ ye bölünerek oranlar matrisi (P) elde edilmiştir. Oranlar matrisinin $\mathrm{z}$ tablo değerleri hesaplanarak birim normal sapmalar matrisi $(Z)$ elde edilmiştir. $S_{j}$ ölçek değerleri $Z$ matrisindeki sütun elemanlarının toplamının, $\mathrm{K}$ uyarıcı sayısına bölünmesi ile elde edilmiştir. En küçük ortalama sıfıra getirilerek, $\mathrm{S}_{\mathrm{c}}$ ölçek değerleri elde edilmiştir.

Son olarak her iki ölçekleme yönteminden elde edilen ölçek değerleri arasındaki tutarlığı incelemek için Spearman-Brown sıra farkları korelasyon katsayısı $\left(\mathrm{r}_{\mathrm{s}}\right)$ hesaplanmıştır.

\section{BULGULAR}

\section{Birinci Alt Probleme İlişkin Bulgular}

$\mathrm{Bu}$ alt problemde "İkili karşılaştırma yargılarına dayalı ölçekleme yönteminden elde edilen madde ölçek değerleri nasıldır?” sorusuna yanıt aranmıştır. İkili karşılaştırmalar yargıları ile ölçekleme için oluşturulan forma gözlemcilerin verdikleri yanıtlar ile oluşturulan frekans tablosu Tablo 1'deki gibidir. 
Tablo 1. İkili Karşılaştırma Yargılarına Dayalı Sekiz Duruma Ait Ham Puanlar Matrisi (F)

\begin{tabular}{lllllllll}
\hline & & \multicolumn{1}{c}{$\mathrm{Uj}$} \\
\hline Uk & $\mathrm{U} 1$ & $\mathrm{U} 2$ & $\mathrm{U} 3$ & $\mathrm{U} 4$ & $\mathrm{U} 5$ & $\mathrm{U} 6$ & $\mathrm{U} 7$ & $\mathrm{U} 8$ \\
U1: Arama motorlarında araştırma yapmak & - & 169 & 114 & 188 & 116 & 114 & 153 & 85 \\
U2: Ders dokümanlarını paylaşmak & 25 & - & 70 & 177 & 76 & 66 & 149 & 76 \\
U3: E-posta göndermek & 80 & 124 & - & 180 & 103 & 81 & 144 & 62 \\
U4: Alışveriş yapmak & 6 & 17 & 14 & - & 6 & 6 & 37 & 12 \\
U5: Müzik/video dinlemek/indirmek & 78 & 118 & 91 & 188 & - & 93 & 153 & 52 \\
U6: Sohbet etmek (yahoo, msn vb) & 80 & 128 & 113 & 188 & 101 & - & 114 & 153 \\
U7: Oyun oynamak & 41 & 45 & 50 & 157 & 41 & 80 & - & 157 \\
U8: Sosyal paylaşım ağlarına girmek & 109 & 118 & 132 & 182 & 142 & 41 & 37 & - \\
(facebook/ twitter vb) & 417 & 720 & 584 & 1261 & 584 & 481 & 788 & 598 \\
\hline Toplam & & & & & & &
\end{tabular}

Öğretmen adayları interneti kullanım amaçlarını ikili olarak karşılaştırılmış, ve her bir uyarıcıya ait frekans değerlerini gösteren ham puanlar matrisi (F) oluşturulmuştur. Frekans matrisi, satırdaki uyarıcının sütundaki uyarıcıya göre tercih edilme durumunu ifade etmektedir. Örneğin, U1 uyarıcısını U2 uyarıcısına tercih edenlerin sayıs1 169'dur. Benzer şekilde U2 uyarıcısını U1 uyarıcısına tercih edenlerin sayısı 25'tir. Bu durumda F matrisinin satır toplamları o uyarıcının tercih edilme sayısını göstermektedir. Ardından frekans matrisinin her bir elemanı ikili karşılaştırmayı yapan öğretmen adayı sayısına bölünerek oranlar matrisi $(\mathrm{P})$ bulunmuştur. Tablodaki $\mathrm{F}$ matrisinin her bir elemanı öğretmen adayı sayısı olan 194'e bölünmüş ve P matrisi hesaplanmıştır. Tablo 2'de oranlar matrisine yer verilmiştir.

Tablo 2. Sekiz Duruma Ait Oranlar Matrisi (P)

\begin{tabular}{llllllllll}
\hline & & \multicolumn{1}{c}{ Uj } \\
\hline Uk & $\mathrm{U} 1$ & $\mathrm{U} 2$ & $\mathrm{U} 3$ & $\mathrm{U} 4$ & $\mathrm{U} 5$ & $\mathrm{U} 6$ & $\mathrm{U} 7$ & $\mathrm{U} 8$ \\
U1: Arama motorlarında araştırma yapmak & - & 0,87 & 0,59 & 0,97 & 0,60 & 0,59 & 0,79 & 0,44 \\
U2: Ders dokümanlarını paylaşmak & 0,13 & - & 0,36 & 0,91 & 0,39 & 0,34 & 0,77 & 0,39 \\
U3: E-posta göndermek & 0,41 & 0,64 & - & 0,93 & 0,53 & 0,42 & 0,74 & 0,32 \\
U4: Alışveriş yapmak & 0,03 & 0,09 & 0,07 & - & 0,03 & 0,03 & 0,19 & 0,06 \\
U5: Müzik/video dinlemek/indirmek & 0,40 & 0,61 & 0,47 & 0,97 & - & 0,48 & 0,79 & 0,27 \\
U6: Sohbet etmek (yahoo, msn vb) & 0,41 & 0,66 & 0,58 & 0,97 & 0,52 & - & 0,59 & 0,79 \\
U7: Oyun oynamak & 0,21 & 0,23 & 0,26 & 0,81 & 0,21 & 0,41 & - & 0,81 \\
U8: Sosyal paylaşım ağlarına girmek & 0,56 & 0,61 & 0,68 & 0,94 & 0,73 & 0,21 & 0,19 & - \\
(facebook/ twitter vb) & & & & & & & & &
\end{tabular}

Tablo 2'deki P matrisi incelendiğinde matrisin esas köşegenine simetrik olan oranlarının toplamının 1 olduğu görülmektedir. Tablo 2'de elde edilen $\mathrm{P}$ matrisi birim normal sapmalar (Z) matrisinin hesaplanabilmesi için kullanılmıştır. $P$ matrisinin elemanlarına karşı gelen $\mathrm{z}$ değerleri belirlenerek Tablo 3'te verilen birim normal sapmalar (Z) matrisi elde edilmiştir. 
Tablo 3. Birim Normal Sapmalar Matrisi (Z) ve Ölçek Değerleri

\begin{tabular}{lclllllll}
\hline & \multicolumn{1}{c}{$\mathrm{Uj}$} \\
\hline Uk & $\mathrm{U} 1$ & $\mathrm{U} 2$ & $\mathrm{U} 3$ & $\mathrm{U} 4$ & $\mathrm{U} 5$ & $\mathrm{U} 6$ & $\mathrm{U} 7$ & $\mathrm{U} 8$ \\
U1: Arama motorlarında araştırma yapmak & - & 1,11 & 0,22 & 1,83 & 0,25 & 0,22 & 0,80 & $-0,14$ \\
U2: Ders dokümanlarını paylaşmak & $-1,11$ & - & $-0,37$ & 1,35 & $-0,28$ & $-0,40$ & 0,73 & $-0,28$ \\
U3: E-posta göndermek & $-0,22$ & 0,37 & - & 1,50 & 0,08 & $-0,20$ & 0,66 & $-0,46$ \\
U4: Alı̧veriş yapmak & $-1,83$ & $-1,35$ & $-1,50$ & - & $-1,83$ & $-1,83$ & $-0,88$ & $-1,59$ \\
U5: Müzik/video dinlemek/indirmek & $-0,25$ & 0,28 & $-0,08$ & 1,83 & - & $-0,06$ & 0,80 & $-0,62$ \\
U6: Sohbet etmek (yahoo, msn vb) & $-0,22$ & 0,40 & 0,20 & 1,83 & 0,06 & - & 0,22 & 0,80 \\
U7: Oyun oynamak & $-0,80$ & $-0,73$ & $-0,66$ & 0,88 & $-0,80$ & $-0,22$ & - & 0,88 \\
U8: Sosyal paylaşım ağlarına girmek & 0,14 & 0,28 & 0,46 & 1,59 & 0,62 & $-0,80$ & $-0,88$ & - \\
(facebook/ twitter vb) & $-4,31$ & 0,37 & $-1,73$ & 10,83 & $-1,90$ & $-3,29$ & 1,45 & $-1,41$ \\
Toplam & $-0,54$ & 0,05 & $-0,22$ & 1,35 & $-0,24$ & $-0,41$ & 0,18 & $-0,18$ \\
Sj & 0,00 & 0,59 & 0,32 & 1,89 & 0,30 & 0,13 & 0,72 & 0,36 \\
Sc & & & & & & & &
\end{tabular}

Tablo 3'te verilen Z matrisinin elemanları, esas köşegene göre mutlak değer olarak eşit ve işaret yönünden terstir. Tablo 3 'teki matrisin her bir sütunun toplamları bulunarak toplam $\left(\Sigma Z_{\mathrm{j}}\right)$ satırına yazılmıştır. $\mathrm{Z}$ matrisindeki sütun elemanlarının ortalaması alınarak $\mathrm{S}_{\mathrm{j}}$ ölçek değerleri elde eldir. Eksenin başlangıç noktasını sıfıra kaydırmak için en küçük ölçek değeri sıfıra getirilerek internet kullanım amaçları uyarıcılarına ait $S_{c}$ ölçek değerleri elde edilmiştir.

Elde edilen interneti kullanım amaçları uyarıcılarına ait ölçek değerlerinin güvenilir olup olmadığını kontrol etmek için ortalama hata değeri hesaplanmıştır. Ortalama hata, gözlenen değerlerle ampirik değerler arasında uyumun ortalama değerini yani uyumun bir ölçüsünü vermektedir. Bu uygunluk derecesinin anlamlı olup olmadığını yoklamak için ise ki-kare değeri hesaplanmıştır.

Verilere ilişkin ortalama hata değeri aşağıdaki eşitlik yardımıyla hesaplanmıştır.

$$
\mathrm{OH}=\Sigma \mid \mathrm{p}_{\mathrm{jk}}-\mathrm{p}_{\mathrm{jk}}^{\prime} / \mathrm{K}(\mathrm{K}-1)
$$

$\mathrm{OH}=$ Gözlenen oranla teorik oran arasındaki farkın ortalama değeri (Ortalama Hata)

$\mathrm{p}_{\mathrm{jk}}=$ Gözlenen frekanslardan elde edilen oran

$\mathrm{p}_{\mathrm{jk}}^{\prime}=$ Teorik oran

$\mathrm{K}=$ uyarıc1 sayıs 1

Analiz sonucunda ortalama hata değeri 0,044 olarak hesaplanmıştır. Elde edilen bu ortalama hata değerinin düşük düzeyde olduğu ifade edilebilir ve bu değere bakılarak ölçek değerlerinin güvenilir olduğu söylenebilir. Ortalama hata değerinin anlamlılığına ilişkin yapılan ki-kare analizi sonucunda ki kare $\left(\chi^{2}\right)$ değeri 117,87 olarak hesaplanmıştır $\left(\chi^{2}\right.$ tablo değeri; $\left.\chi_{(0,05 ; 21)}^{2}=32,67\right)$. Hesaplanan ki kare değeri anlamlı bulunmadığ 1 için Guilford (1954)'un önerdiği III. hal denklemi ile ölçekleme yapılmış ve her bir varyans tek tek hesaplanmıştır. Elde edilen değerler Tablo 4'te verilmiştir. 
Albayrak Sarı, A., Gelbal, S.

Tablo 4. Birim Normal Standart Sapmalar Matrisi ve Varyans Değerleri

\begin{tabular}{lclllllll}
\hline & & \multicolumn{7}{c}{$\mathrm{Uj}$} \\
\hline $\mathrm{Uk}$ & $\mathrm{U} 1$ & $\mathrm{U} 2$ & $\mathrm{U} 3$ & $\mathrm{U} 4$ & $\mathrm{U} 5$ & $\mathrm{U} 6$ & $\mathrm{U} 7$ & $\mathrm{U} 8$ \\
$\mathrm{U} 1$ & - & 1,11 & 0,22 & 1,83 & 0,25 & 0,22 & 0,80 & $-0,14$ \\
$\mathrm{U} 2$ & $-1,11$ & - & $-0,37$ & 1,35 & $-0,28$ & $-0,40$ & 0,73 & $-0,28$ \\
$\mathrm{U} 3$ & $-0,22$ & 0,37 & - & 1,50 & 0,08 & $-0,20$ & 0,66 & $-0,46$ \\
$\mathrm{U} 4$ & $-1,83$ & $-1,35$ & $-1,50$ & - & $-1,83$ & $-1,83$ & $-0,88$ & $-1,59$ \\
$\mathrm{U} 5$ & $-0,25$ & 0,28 & $-0,08$ & 1,83 & - & $-0,06$ & 0,80 & $-0,62$ \\
$\mathrm{U} 6$ & $-0,22$ & 0,40 & 0,20 & 1,83 & 0,06 & - & 0,22 & 0,80 \\
$\mathrm{U} 7$ & $-0,80$ & $-0,73$ & $-0,66$ & 0,88 & $-0,80$ & $-0,22$ & - & 0,88 \\
$\mathrm{U} 8$ & 0,14 & 0,28 & 0,46 & 1,59 & 0,62 & $-0,80$ & $-0,88$ & - \\
\hline Toplam Zj & $-4,31$ & 0,37 & $-1,73$ & 10,83 & $-1,90$ & $-3,29$ & 1,45 & $-1,41$ \\
Toplam $\left(\mathrm{Zj}{ }^{2}\right)$ & 0,00 & 0,00 & 0,00 & 0,00 & 0,00 & 0,00 & 0,00 & 0,00 \\
$\mathrm{~K} *\left(\right.$ Toplam $\left.\left(\mathrm{Zj}{ }^{2}\right)\right)$ & 0,00 & 0,00 & 0,00 & 0,00 & 0,00 & 0,00 & 0,00 & 0,00 \\
Toplam Zj) & 18,58 & 0,14 & 2,99 & 117,20 & 3,62 & 10,82 & 2,10 & 2,00 \\
Vj & 0,63 & 0,76 & 0,62 & 0,32 & 0,76 & 0,63 & 0,71 & 0,79 \\
$\mathrm{~K} * \mathrm{Vj}$ & 5,03 & 6,06 & 4,97 & 2,59 & 6,07 & 5,03 & 5,70 & 6,32 \\
$1 /\left(\mathrm{K}^{*} \mathrm{Vj}\right)$ & 0,20 & 0,17 & 0,20 & 0,39 & 0,16 & 0,20 & 0,18 & 0,16 \\
Toplam $(1 / \mathrm{Vj})$ & 1,65 & & & & & & & \\
KC & 9,71 & 9,71 & 9,71 & 9,71 & 9,71 & 9,71 & 9,71 & 9,71 \\
Std kayma & 0,93 & 0,60 & 0,95 & 2,75 & 0,60 & 0,93 & 0,70 & 0,54 \\
Varyans & 0,86 & 0,36 & 0,91 & 7,56 & 0,36 & 0,87 & 0,49 & 0,29 \\
\hline
\end{tabular}

Elde edilen bu varyans değerleri kullanılarak, varyans toplamlarının karekökü matrisi oluşturulmuştur. Daha sonra bu değerler Z birim normal sapmalar matrisi ile çarpılmış ve;

$$
S_{j}-S_{k}=Z_{j k} \cdot\left(\sigma_{j}^{2}+\sigma_{k}^{2}\right)
$$

eşitliği yardımıyla $\mathrm{S}$ matrisi elde edilmiştir. Tablo 5'te verilen $\mathrm{S}$ matrisinin sütun elemanları ortalaması bize $\mathrm{Sj}$ ölçek değerlerini verir. En küçük değer sıfıra kaydırılarak Sc ölçek değerleri elde edilir.

Tablo 5. S Matrisi ve Ölçek Değerleri

\begin{tabular}{lllllllll}
\hline & \multicolumn{7}{c}{$\mathrm{Uj}$} \\
\hline U1 & $\mathrm{U} 1$ & $\mathrm{U} 2$ & $\mathrm{U} 3$ & $\mathrm{U} 4$ & $\mathrm{U} 5$ & $\mathrm{U} 6$ & $\mathrm{U} 7$ & $\mathrm{U} 8$ \\
U2 & 0,00 & 1,22 & 0,25 & 1,42 & 0,28 & 0,53 & 0,65 & $-0,27$ \\
U3 & $-1,22$ & 0,00 & $-0,44$ & 1,20 & $-0,34$ & $-0,96$ & 0,67 & $-0,56$ \\
U4 & $-0,25$ & 0,44 & 0,00 & 1,36 & 0,10 & $-0,47$ & 0,61 & $-0,92$ \\
U5 & $-1,42$ & $-1,20$ & $-1,36$ & 0,00 & $-1,67$ & $-4,17$ & $-0,44$ & $-2,92$ \\
U6 & $-0,28$ & 0,34 & $-0,10$ & 1,67 & 0,00 & $-0,13$ & 0,75 & $-1,24$ \\
U7 & $-0,53$ & 0,96 & 0,47 & 4,17 & 0,13 & 0,00 & 0,51 & 2,32 \\
U8 & $-0,65$ & $-0,67$ & $-0,61$ & 0,44 & $-0,75$ & $-0,51$ & 0,00 & 1,63 \\
\hline Toplam Zj & 0,27 & 0,56 & 0,92 & 2,92 & 1,24 & $-2,32$ & $-1,63$ & 0,00 \\
Sj & $-4,07$ & 1,65 & $-0,87$ & 13,17 & $-1,00$ & $-8,04$ & 1,13 & $-1,97$ \\
& $-0,51$ & 0,21 & $-0,11$ & 1,65 & $-0,12$ & $-1,00$ & 0,14 & $-0,25$
\end{tabular}




\begin{tabular}{lllllllll}
\hline III. Hal Sc & 0,50 & 1,21 & 0,90 & 2,65 & 0,88 & 0,00 & 1,15 & 0,76 \\
\hline
\end{tabular}

$\mathrm{Z}$ matrisindeki sütun elemanlarının ortalaması alınarak $\mathrm{Sj}$ ölçek değerleri elde eldir. En küçük ortalama sıfıra getirilerek, Sc ölçek değerleri Tablo 6'da verildiği gibi elde edilmiştir.

Tablo 6. İkili Karşılaştırma Yargılarının III. Hal Denklemi ile Ölçeklenmesinden Elde Edilen Ölçek Değerlerinin Stralı Olarak Gösterimi

\begin{tabular}{lll}
\hline Siraları & Ölçek Değerleri $\left.\mathbf{( S}_{\mathbf{c}}\right)$ & Uyarıcılar \\
\hline 1 & 0,00 & U6: Sohbet etmek (yahoo, msn vb) \\
2 & 0,50 & U1: Arama motorlarında araştırma yapmak \\
3 & 0,76 & U8: Sosyal paylaşım ağlarına girmek (facebook/ twitter vb) \\
4 & 0,88 & U5: Müzik/video dinlemek/indirmek \\
5 & 0,90 & U3: E-posta göndermek \\
6 & 1,15 & U7: Oyun oynamak \\
7 & 1,21 & U2: Ders dokümanlarını paylaşmak \\
8 & 2,65 & U4: Alışveriş yapmak \\
\hline
\end{tabular}

Fen Bilgisi öğretmen adaylarının interneti kullanım amaçları Tablo 6'daki gibi sıralanmıştır. Aday öğretmenlerin birinci sırada sohbet etmek amacı ile interneti kullandıkları görülmektedir. $\mathrm{Bu}$ amacı sırasıyla, arama motorlarında arama yapmak, müzik/video dinlemek/indirmek, e-posta göndermek, sosyal paylaşım ağlarına girmek, ders dokümanlarını paylaşmak ve oyun oynamak izlemektedir. Öğretmen adaylarının interneti kullanma amaçları içinde en son sırayı alışveriş yapmanın aldığı gözlenmiştir.

\section{İkinci Alt Probleme İlişkin Bulgular}

$\mathrm{Bu}$ alt problemde "Sıralama yargılarına dayalı ölçekleme yönteminden elde edilen madde ölçek değerleri nasıldır?” sorusuna yanıt aranmıştır. Sıralama yargıları ile ölçekleme için oluşturulan forma öğretmen adaylarının verdikleri yanıtlar ile oluşturulan, sekiz duruma ait sıra frekansları matrisi Tablo 7'deki gibidir.

Tablo 7. Siralama Yargılarına Dayalı Sekiz Duruma Ait Ham Puanlar Matrisi (F)

\begin{tabular}{llllllllll}
\hline & $\mathrm{U} 1$ & $\mathrm{U} 2$ & $\mathrm{U} 3$ & $\mathrm{U} 4$ & $\mathrm{U} 5$ & $\mathrm{U} 6$ & $\mathrm{U} 7$ & $\mathrm{U} 8$ & Toplam \\
\hline $\mathrm{U} 1$ & 101 & 32 & 19 & 6 & 15 & 6 & 6 & 6 & 194 \\
$\mathrm{U} 2$ & 2 & 47 & 43 & 32 & 28 & 28 & 6 & 6 & 194 \\
$\mathrm{U} 3$ & 13 & 32 & 52 & 32 & 34 & 13 & 17 & 0 & 194 \\
$\mathrm{U} 4$ & 13 & 2 & 0 & 11 & 4 & 11 & 30 & 123 & 194 \\
$\mathrm{U} 5$ & 9 & 15 & 30 & 43 & 26 & 60 & 9 & 2 & 194 \\
$\mathrm{U} 6$ & 13 & 22 & 30 & 37 & 45 & 34 & 9 & 4 & 194 \\
U7 & 17 & 0 & 2 & 6 & 19 & 24 & 88 & 37 & 194 \\
U8 & 26 & 43 & 17 & 26 & 22 & 17 & 28 & 15 & 194 \\
\hline Toplam & 194 & 194 & 194 & 194 & 194 & 194 & 194 & 194 & 1552 \\
\hline
\end{tabular}

Tablo 7'de verilen frekans matrisindeki frekanslar $\mathrm{N}^{2}$ ye bölünerek P oranlar matrisi elde edilmiş ve $\mathrm{P}$ oranlar matris elemanlarına karşılık gelen $\mathrm{z}$ değerleri kontrol edilerek Tablo 8'de verilen $\mathrm{Z}$ birim matrisi elde edilmiştir. 
Tablo 8. Z Birim Matrisi ve Ölçek Değerleri

\begin{tabular}{lclllllll}
\hline & & \multicolumn{7}{c}{$\mathrm{Uj}$} \\
\hline Uk & $\mathrm{U} 1$ & $\mathrm{U} 2$ & $\mathrm{U} 3$ & $\mathrm{U} 4$ & $\mathrm{U} 5$ & $\mathrm{U} 6$ & $\mathrm{U} 7$ & $\mathrm{U} 8$ \\
$\mathrm{U} 1$ & - & $-0,30$ & $-0,28$ & $-0,45$ & $-0,42$ & $-0,49$ & $-0,67$ & $-0,47$ \\
U2 & 0,30 & - & $-0,01$ & $-0,22$ & $-0,20$ & $-0,27$ & $-0,50$ & $-0,31$ \\
U3 & 0,28 & 0,01 & - & $-0,27$ & $-0,27$ & $-0,37$ & $-0,70$ & $-0,39$ \\
U4 & 0,45 & 0,22 & 0,27 & - & $-0,02$ & $-0,11$ & $-0,44$ & $-0,02$ \\
U5 & 0,42 & 0,20 & 0,27 & 0,02 & - & $-0,06$ & $-0,43$ & $-0,05$ \\
U6 & 0,49 & 0,27 & 0,37 & 0,11 & 0,06 & - & $-0,36$ & 0,17 \\
U7 & 0,67 & 0,50 & 0,70 & 0,44 & 0,43 & 0,36 & - & 0,38 \\
U8 & 0,47 & 0,31 & 0,39 & 0,02 & 0,05 & $-0,17$ & $-0,38$ & - \\
\hline Toplam & 3,08 & 1,21 & 1,71 & $-0,35$ & $-0,37$ & $-1,11$ & $-3,48$ & $-0,69$ \\
Sj & 0,39 & 0,15 & 0,21 & $-0,04$ & $-0,05$ & $-0,14$ & $-0,44$ & $-0,09$ \\
Sc & 0,82 & 0,59 & 0,65 & 0,39 & 0,39 & 0,30 & 0,00 & 0,35 \\
\hline
\end{tabular}

Tablo 8'de belirtilen $\mathrm{Z}$ matrisindeki sütun elemanlarının toplamının, $\mathrm{K}$ uyarıcı sayısına bölünmesi ile $S_{j}$ ölçek değerleri elde edilmiştir. En küçük ortalama sıfıra getirilerek, $S_{\mathrm{c}}$ ölçek değerleri bulunmuştur. $S_{c}$ ölçek değerleri Tablo 9' da verildiği gibi elde edilmiştir.

Tablo 9. Sıralama Yargıları ile Elde Edilen Ölçek Değerlerinin Sıralı Olarak Gösterimi

\begin{tabular}{lll}
\hline Uyarıcılar & Ölçek Değerleri $\mathbf{( \mathbf { S } _ { \mathbf { c } } )}$ & Sıraları \\
\hline U7: Oyun oynamak & 0,00 & 1 \\
U6: Sohbet etmek (yahoo, msn vb) & 0,30 & 2 \\
U8: Sosyal paylaşım ağlarına girmek (facebook/ twitter vb) & 0,35 & 3 \\
U5: Müzik/video dinlemek/indirmek & 0,39 & 4 \\
U4: Alışveriş yapmak & 0,39 & 5 \\
U2: Ders dokümanlarını paylaşmak & 0,59 & 6 \\
U3: E-posta göndermek & 0,65 & 7 \\
U1: Arama motorlarında araştırma yapmak & 0,82 & 8 \\
\hline
\end{tabular}

Fen bilgisi öğretmen adaylarının internet kullanım amaçlarının belirlenebilmesi için, uygulanan ölçekten elde edilen veriler sıralama yargılarına dayalı olarak ölçeklenmiştir. Bu ölçeklemenin sonucunda öğretmen adaylarının internet kullanım amaçlarının Tablo 9'daki gibi sıralandığı görülmektedir. Öğretmen adaylarının ikili karşılaştırma ile ölçekleme de olduğu gibi yine birinci sırada oyun oynamayı tercih ettikleri görülmektedir. $\mathrm{Bu}$ amacı, sohbet etmek, sosyal paylaşım ağlarına girmek, müzik/video dinlemek/indirmek, alış veriş yapmak, ders dokümanlarını paylaşmak, e-posta göndermek izlemektedir. Öğretmen adaylarının interneti kullanma amaçları içinde en son sırayı ise arama motorlarında araştırma yapmanın aldığı gözlenmiştir.

\section{Üçüncü Alt Probleme İlişkin Bulgular}

$\mathrm{Bu}$ alt problemde "İkili karşılaştırma yargılarına dayalı olarak elde edilen ölçek değerleri ile sıralama yargılarına dayalı olarak elde edilen ölçek değerleri arasında nasıl bir ilişki vardır?” sorusuna yanıt aranmıştır. Her iki ölçekleme yöntemine göre elde edilen bulgular Tablo 10 'da verilmiştir. 
Tablo 10. İkili Karşılaştırma Yargılarının III. Hal Denklemi ile Ölçeklenmesinden Elde Edilen Ölçek Değerleri ve Stralama Yarglları ile Ölçeklemeden Elde Edilen Ölçek Değerleri

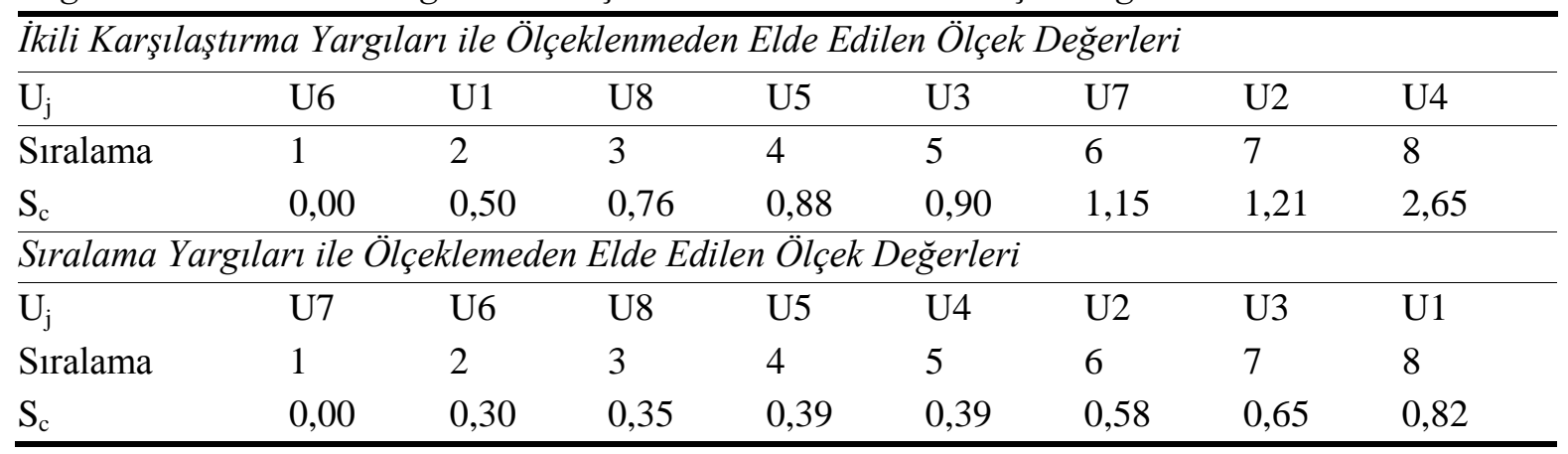

Bu bulgular ikili karşılaştırma yargılarına dayalı olarak belirlenen ölçek değerleriyle karşılaştırıldığında; Sosyal paylaşım ağlarına girmek (U8) ve Müzik/video dinlemek/indirmek (U5) hem ikili karşılaştırma yargılarına dayalı hem de sıralama yargılarına dayalı ölçek değerlerinin aynı sıralara sahip olduğu; Sohbet etmek (U6) ve Ders dokümanlarını paylaşmak (U2) birbirine yakın, Arama motorlarında araştırma yapmak (U1), E-posta göndermek (U3), Alışveriş yapmak (U4) ve Oyun oynamak (U7) ölçek değerlerinin ise farklı sıralara sahip olduğu gözlenmiştir.

İkili karşılaştırma yargılarına ve sıralama yargılarına dayalı ölçeklemeden elde edilen ölçek değerleri (uyarıcılar tarafından algılanan büyüklükleri) arasındaki tutarlığın derecesini belirlemek için bu iki yaklaşıma göre elde edilen ölçek değerleri arasında Spearman-Brown rho sıra farkları korelasyon katsayısı hesaplanmıştır $(r=0.095, p>0.05)$. Bu bulguya göre, ikili karşılaştırma yöntemiyle elde edilen ölçek değerleri ile sıralama yargılarına dayalı ölçekleme yöntemlerinden elde edilen ölçek değerleri arasında anlamlı bir ilişki olmadığı görülmektedir.

\section{SONUÇLAR ve TARTIŞMA}

Ölçekleme teknikleri, fiziksel büyüklüklerin insan duyularınca nasıl algılandığını ortaya çıkarma, uyarıcıların ölçülen büyüklükleri ile algılanan büyüklükleri arasındaki bağıntıyı belirlemeyi amaçlayan bir bilim dalı olan psikofizik alanına ait bir disiplindir (Kan, 2008a). $\mathrm{Bu}$ çalışmada, yargıcı kararlarının ikili karşılaştırma yargıları ile veya sıralama yargıları ile elde edilmiş olmasının, uyarıcıların psikofiziksel boyuttaki yerlerini etkileyip etkilemediği araştırılmıştır.

İkili karşılaştırmalar yargılarına dayalı ölçekleme yöntemine göre ölçekleme yapıldığında öğretmen adayları tarafından internetin en çok "sohbet etmek" nedeni ile kullanıldığını belirttikleri bulunmuştur. Ardından sırasıyla "arama motorlarında araştırma yapmak" ve "sosyal paylaşım sitelerine girmek" nedenleri gelmektedir.

Sıralama yargılarına dayalı yöntemle ölçekleme yapıldığında öğretmen adayları tarafından internetin en çok "oyun oynamak" nedeni ile kullanıldığı bulgusuna ulaşılmıştır. Bu nedeni "sohbet etmek" ve "sosyal paylaşım ağlarına girmek” izlemektedir.

Çalışmanın diğer bir araştırma problemi, kullanılan yargıcı kararlarına dayalı yaklaşımlardan iki ölçekleme yönteminin birbiriyle tutarlı sonuçlar üretip üretmediğinin belirlenmesidir. İkili karşılaştırma yargıları ve sıralama yargılarına göre toplanan veriler üzerinde yapılan tutarlık analizi, elde edilen ölçekleme sonuçlarının güvenilir olduğunu göstermektedir. Çalışmanın bulguları, iki farklı yargıcı kararlarına dayalı geliştirilen ölçek 
değerleri arasındaki ilişkinin istatistiksel olarak manidar olmadığını göstermektedir $\left(r_{\mathrm{s}}=0,095, \mathrm{p}>0,05\right)$.

Bu bulgular doğrultusunda bu çalışma, yargıcı kararlarına dayalı ölçekleme çalışması yapılırken kullanılan yöntemin, uyarıcıların ölçek değerleri yani sıralamadaki yerleri üzerinde etkili olduğunu göstermiştir. Bu durumda, gözlemcilerin algılarına dayalı bilgi toplanan bu tür çalışmalarda, yargıcı kararlarının hangi yöntemle elde edildiğine dikkat edilmesi gerekmektedir. Alanyazında farklı ölçekleme yaklaşımlarından elde edilen bulguları karşılaștıran çalıșmalar (O’Neil ve Chissom, 1993; Kan, 2008; Öztürk, Özdemir ve Gelbal, 2011; Acar Güvendir, M. ve Özer Özkan, Y., 2013) oldukça azdır. Bu çalışmalardan elde edilen bulgular ile alanyazındaki bulgular farklılaşmaktadır. Farklı ölçekleme yöntemleri ile elde edilen bulguların tutarlılığını ortaya koyabilmek için farklı ölçekleme yöntemlerinin karşılaştırıldığı çalışmaların sayısının artırılması önerilebilir.

İki ölçekleme yönteminden farklı sonuçlar elde edilmesinin nedeni, Turgut ve Baykul (1992)'un da ifade ettiği gibi; sıra sayılarına dayanan yöntemin sayıtlılarının gerçekleşmesinin çok zor olması olarak ifade edilebilir. Bu nedenle bu yöntemin çok kullanışlı olmadığı belirtilmiştir. Ayrıca, Turgut ve Baykul (1992) sıralama sayılarına uygulanabilecek en tutarlı ölçek değerini veren yöntemin ikili karşılaştırmalar yöntemi olduğunu belirtmiştir.

Kullanılan iki ölçekleme yönteminin benzer sonuçlar üretmediği, kullanılan ölçekleme yönteminin ölçek değerlerini yani uyarıcıların fiziksel boyuttaki yerini etkilediği sonucuna ulaşıldığı için, araştırmacılara yargıcı kararlarının hangi yöntemle elde ettiklerine dikkat etmeleri, en uygun yöntemi seçerken bu durumu göz önünde bulundurmaları önerilebilir.

Ölçekleme yöntemleri ile ilgili çalışma yapacak araştırmacılara; diğer ölçekleme yöntemlerinin birbiri ile tutarlılığını araştırmaları ve sonuçları raporlamaları önerilebilir.

\section{KAYNAKLAR}

Anıl, D. ve Güler, N. (2006). İkili karşılaştırma yöntemi ile ölçekleme çalışmasına bir örnek. Hacettepe Üniversitesi Ĕgitim Fakültesi Dergisi. 30, 30-36.

Acar Güvendir, M. ve Özer Özkan, Y. (2013). İki ölçekleme yönteminin karşılaştırılması: İkili karşılaştırma ve siralama yargiları [A comparison of two scaling methods: Pair wise comparison and rank-order judgments scaling]. Eğitim Bilimleri Araştırmaları Dergisi - Journal of Educational Sciences Research. 3 (1), 105-119. [Online]: http:// http://ebad-jesr.com/ adresinden 12 Mart 2014 tarihinde indirilmiş̧ir.

Altun Akbaba, S. ve Altun, A. (2000). Bir eğitim aracı olarak internet. Milli Eğitim Dergisi. 147, 23-25.

Altun, A. ve Gelbal S. (2014). Öğretmenlerinin Kullandıkları Ölçme ve Değerlendirme Yöntem veya Araçlarının İkili Karşılaştırma Yöntemiyle Belirlenmesi. Eğitimde ve Psikolojide Ölçme ve Değerlendirme Dergisi, 2 (2), 200-209.

Bal, Ö. (2011). Seviye Belirleme Sınavı (SBS) başarısında etkili olduğu düşünülen faktörlerin sıralama yargıları kanunuyla ölçeklenmesi. Eğitimde ve Psikolojide Ölçme ve Değerlendirme Dergisi. 2(2), 200-209.

Brown, T. C. \& Peterson, G. L. (2009). An enquiry into the method of paired comparison: reliability, scaling, and Thurstone's law of comparative judgment. United States Department of Agriculture, Fort Collins.

Crocker, L. \& Algina, J. (1986). Introduction to Classical and Modern Test Theory. New York: CBS College Publishing.

Douglas, A. C., Mills, J. E., Niang, M., Stepchenkova, S., Byun, S., \& Ruffini C., et al. (2008). Internet addiction: Meta-synthesis of qualitative research for the decade 1996-2006. Computers in Human Behavior. 24 , 3027-3044.

Ekinci, A., Bindak, R. ve Yıldırım, C. (2012). İlköğretim okulu yöneticilerinin öğretmenlerin mesleki sorunlarına empatik yaklaşımlarının ikili karşılaş̧ırmalar metodu ile incelenmesi. Gaziantep Üniversitesi Sosyal Bilimler Dergisi. 11 (3), 759-776.

Ergün, M. (1998). İnternet destekli eğitim. Afyon Kocatepe Üniversitesi Sosyal Bilimler Dergisi, 1, 1-10. 
Guilford, J. P. (1954). Psychometrics methods. New York: Mc Graw-Hill Book Co.

Güler, N. ve Anıl, D. (2009). Scaling through pair-wise comparison method in required characteristics of students applying for post graduate programs. International Journal of Human Sciences. 6(1), 627639.

Kan, A. (2008a). Yargıcı kararlarına dayalı ölçekleme yöntemlerinin karşılaştırılması üzerine ampirik bir çalışma. Hacettepe Üniversitesi Ĕgitim Fakültesi Dergisi. 35, 186-194.

Kan, A. (2008b). Psikolojik değişkenleri ölçmek için kullanılan ölçekleme yaklaşımları üzerine bir karşlaştırma. Eğitimde Kuram ve Uygulama. 4(1), 2-18.

O'Neil, M. R. \& Chissom, B. S. (1993). A comparison three methods for assessing attitudes. Annual Meeting of the Educational Research Association. 10-12 November, 1993. New Orleans, USA.

Öğretmen, T. (2008). Alan tercih envanteri: Ölçeklenmesi, geçerliği ve güvenirliği. Türk Eğitim Bilimleri Dergisi. 6(3), 507-522.

Özer, Y. ve Acar, M. (2011). Öğretmenlik mesleği genel yeterlikleri üzerine ikili karşılaştırma yöntemiyle bir ölçekleme çalışması. Çukurova Üniversitesi Eğitim Fakültesi Dergisi. 3 (40), 89-101.

Öztürk, N., Özdemir, S. ve Gelbal, S. (2011). İki farklı ölçekleme yaklaşımından elde edilen ölçek değerleri tutarlılığının incelenmesi. 20. Ulusal Eğitim Bilimleri Kurultayı. 8-10 Eylül 2011. Burdur.

Turgut, M. F. ve Baykul, Y. (1992). Ölçekleme teknikleri. Ankara: ÖSYM Yayınları.

Tezbaşaran (1996). Likert Tipi Ölçek Geliştirme Klavuzu. Ankara: Türk Psikologlar Derneği Yayınları.

Tezbaşaran A. (2004). Likert tipi ölçeklere madde seçmede geleneksel madde analizi tekniklerinin karşılaştırılması. Türk Psikoloji Dergisi. 19 (54), 77-90.

Thurstone, L. L. (1958). A law of comparative judgment. Psychological Review. 34, 273-286.

Torgerson, W. S. (1958). Theory and methods of scaling. New York: John Wiley \& Son.

\section{Introduction}

\section{EXTENDED ABSTRACT}

Scaling processes emerged in the science named psychophysics which concerns to reveal how physical magnitudes are percieved by individuals.Psychophysics science concerns with finding the laws that determines the relationship between the physical values of stimulants and percieved psychological dimension (Turgut and Baykul, 1992). Scaling methods are based on two sources basically, judicial decisions and subject responses. Approaches used in scaling are divided into two: (1) approaches based on subject responses, (2) approaches based on observer judgment. Approaches based on subject responses are named as response approach and approaches based on observer judgments are named as judicial approach. The purpose of scaling is to obtain an unbiased and qualified scale by applying a group of statistical procedures to data obtained from observer judgments and subject responses. In scaling methods based on judicial approach, it is requested from observers to determine the relative status of a stimulus according to other ones, fairly (Torgerson, 1958; Tezbaşaran, 2004). This study aimed to analyze the scaling results and scaling methods based on ranking judgments and pairwise comparison, and determine the consistency by examining the relationship between obtained results. This study tried to answer the questions below for this purpose:

1. How are the item scale values obtained from scaling method based on pairwise comparison judgments?

2. How are the item scale values obtained from scaling method based on ranking judgments?

3. What is the relationship between scaling values obtained based on pairwise comparison judgments and ranking judgments?

\section{Method}

This study is a basic research since it does not have any generalization purpose. The sample set of the research consisted of 194 preservice teacher from the Program of Science Education, Hacettepe University. All the preservice teacher included in the sample set were juniors and seniors and took course of basic computer usage. Two different forms which have different guidelines were prepared for scaling with pairwise comparison judgments and 
ranking judgments. It was requested from each preservice teacher to compare the eight determined purposes dichotomously and determine on which pairwise comparison they use the internet most. Firstly, collected data was scaled with V. Hal equation, harmony(?) measurement of V. Hal scaling was analyzed. After the analysis of chi-square, the data was scaled with III. Hal equation since the data did not procure the assumptions of V. Hal equation. Same stimulants (scale items) were given to 194 preservice teacher for scaling method with ranking judgments and by regarding all the stimulants, it was requested from the preservice teachers to rank the purposes of Internet usage according to frequency of occurrence.

\section{Results and Discussion}

Scaling was performed based on pairwise comparisons and ranking judgments to determine the students' purposes of Internet usage. According to the findings, it was requested from the students to rank the stimulants. According to the scaling method based on pairwise comparison judgments, Internet is mostly used to "chat" by the students. Other purposes are "research on search engine" and "social networks", respectively. According to the scaling method based on ranking judgments, Internet is mostly used to "play games" by the students. Other purposes are "chat" and "social networks", respectively. Another problem of the study is to determine whether two methods based on judgment decisions that used to determine the values of stimulants (psychological properties) produce consistent results with each other. Consistency analysis that applied to data collected according to pairwise comparison judgments and ranking judgments shows the scaling results are reliable enough. Findings of the study show that a low level relationship exists between the scale values developed based on two different judgment decisions $\left(r_{s}=0,095\right)$ and this relationship is not significant $(\mathrm{p}>0,05)$. According to those findings, the study shows the way of obtaining judgment decisions, which are used on scaling study based on judgment decisions, is effective on the stimulants' locations on the physical dimensions. Therefore, it should be paid attention that by which method the judgment decisions are obtained in the studies that collects information according to observer perceptions. 